\title{
Sustaining Healthcare: Bridging Education with Biomedical and Healthcare Challenges
}

\author{
By Paraskevi Papadopoulou ${ }^{1}$, Christina Marouli ${ }^{1}$, Anastasia Misseyanni ${ }^{1}$
}

\begin{abstract}
Major advances and breakthroughs in Medicine and Healthcare are transforming our world. How will we manage to tackle our disease burden to improve our day-to-day well-being especially if in developed countries the global population of people over 80 will more than triple by 2050 and in the less developed ones the youth profile will escalate? Will Europeans as an example, find ways to balance budgets and restrain spending and come up with a sustainable survival strategy for Europe's healthcare systems? This work addresses a number of challenging questions and offers "smart" solutions and a framework on how to develop and sustain new models of care and improve the public services profile with the vision to become globally leading healthcare institutions mainly in Europe and particularly in Greece. The nature of programs in biomedical and healthcare sciences, the kind of educators and healthcare professionals and how to technologically and practically support such programs is considered. How to connect Biomedical programs with Medical Centers and what kind of student internships can be developed is discussed. What it means to have patient-centered medical centers which abide by strict European and international guidelines and certifications and how to provide top quality medical services is also examined.
\end{abstract}

Keywords: Education, Healthcare, Medicine, Biomedical Programs, Smart Solutions, Internships, International Certifications

\section{Introduction}

The present time is extraordinary in terms of challenges related to the environment and spaces we live in, the type of education we receive, the need for clean water and food, for energy and other resources, including the type of governance and security we experience. Rapid high technology changes and reforms are happening in all those areas, and we hope that they will lead to incredible opportunities rather than failures and that we, humans, will rise to the challenges to bring about prosperity and improvement in our standards of life. According to "Health 2020", a European policy framework supporting action across government and society for health and well-being, good health is considered as a valuable societal resource and asset worth our attention (WHO, 2019; WHO, 2020; OECD, 2017a; OECD, 2017b; OECD, 2019a; Eurostat, 2020; World Bank, 2019).

In this context, and taking into account the obstacles and challenges we face, major advances and breakthroughs in medicine and healthcare have begun to transform our world already. Yet, not all nations have a clear vision of how such transformation should take place or how in the end it will offer hope and purpose or some clarity to all on what it means to live a healthy life. The 17 UN Sustainable Development Goals (SDGs), the 
Global Action Plan for the Prevention and Control of Noncommunicable diseases (NCDs) 2013-2020 and the European Regional Health Policy Framework "Health 2020" are the three guiding frameworks for progress on health and wellbeing (WHO, 2013). Despite the worldwide efforts to reduce poverty and improve the education and health status of nations, we have fallen behind meeting such goals as equity and fair distribution of resources. A good number of people from all countries raise numerous concerns on the features of this international vision and it is obvious some countries are lagging in their reforms. A major issue raised, as an example, is the way to manage and tackle our disease burden to improve our day-to-day well-being, especially if in developed countries the global population of people over 80 will more than triple by 2050 and in the less developed ones, the youth profile will escalate much beyond any previous numbers (WHO, 2019; WHO, 2020). Such issues will require major and 'smart' reforms in order to find ways to balance budgets, restrain spending and come up with a sustainable survival strategy for healthcare systems. Sustainable healthcare systems nevertheless, come along with 'healthy' economies, which have revived productivity and have managed to boost income in the long term. This in 'healthy' economies leads to decomposition of GDP growth into labor productivity and labor utilization. Inclusiveness and environmental sustainability are taken into consideration, thus leading to best available outcome and policy indicators which will help the nations set priorities related to education and wellbeing (WHO, 2019; WHO, 2020; OECD, 2017a,b; OECD, 2019a).

Governments therefore, all around the world are expected to address and to respond to such challenges which result from issues of globalization, trade conflicts, geopolitical tensions, climate change, environmental degradation, including the aging of the population of developed countries, together with financial issues of various kinds and policy uncertainty. Global trade is stagnating and the economic activity is low in many countries. If the living standards and wellbeing are to be improved, then governments ought to come up with environmentally sustainable reforms the soonest possible (OECD 2019a; OECD 2019b). We need urgent coordinated political action to restore confidence, boost inclusive growth and raise living standards.

On the positive side, despite the many global economy challenges and the high trade uncertainty, numerous policy makers have developed a set of country-specific reform priorities to reverse the current challenges to opportunities for all. (Economou, Kaitelidou, Kentikelenis, Maresso \& Sisouras, 2015); (Economou, Kaitelidou, Karanikolos \& Maresso, 2017). A good number of such reforms have already been implemented and they seem to ensure stronger and fairer outcomes by boosting inclusive growth. Education then becomes a high reform priority which should ensure future generations a fair and rewarding employment and a satisfactory life all together (WHO 2019; WHO 2020; OECD 2017; OECD 2019a).

\section{This Study: Aims and Methodology}

Starting from an examination of the state of health and the state of education in Europe and particularly in Greece, this study examines the following two main research questions with three parts each are examined: What type of educational programs exist in biomedical and healthcare sciences in Europe and in Greece? What is needed to create top medical centers 
of excellence? Our study mainly focuses on the bridging of education with biomedical and healthcare systems in Europe and Greece in particular, by proposing a multidimensional framework, leading to practical applications ranging from the need to explore genomics and proteomics data, utilize exposome analysis to the use of various applications of ICTs in healthcare and personalized medicine which will help the countries to achieve sustainable and healthy societies. In this study, our vision for Greece and Europe as well, aligns with the widely held common vision that asks for a) the improvement of our biomedical and healthcare programs and b) the transformation of the health institutions into globally leading healthcare institutions.

The methodology used in this study combines a review of literature and European reports on education and health country status; use and comparison of country profiles from Eurostat databases and the European Observatory on Health Systems and Policies (OECD); as well as an examination of current trends and Greece's responsibilities to calls for reforms.

\section{Greece: Some Background Information}

Greece's economic recovery especially after many years of unprecedented depression is finally catching up. The pace of reforms has accelerated leading to fiscal credibility. Due to large fiscal adjustments the imbalances in public finances and the current account has improved (Economou et al. 2015); (Economou et al. 2017). GDP per capita is recovering from the long recession but remains half of that of the upper half of OECD countries. GDP is projected to expand by 2\% in 2020-21 (OECD 2019a). Reforms to better support the poor households and to strengthen the revenue collection are partly in place. The life expectancy in Greece is 81.4 years (males: 78.5 years; females 83.7 years) higher than the average OECD countries (males: 77.9 years; females /83.1 years), while ischaemic mortality in Greece is lower than the average of OECD countries (i.e. 82.0 vs 112.0 per 100.000 in Greece and OECD respectively). Chronic disease morbidity is at $4.6 \% / 6.45 \%$ of OECD countries. Yet, mortality due to cancers is high in Greece and Greece has the highest rate of smokers $27.3 \%$ in comparison to $16.4 \%$ in OECD countries. For alcohol consumption 6.5 liter/8.9 liter OECD. Obesity is also high, slightly less than OECD countries 55.0\%/55.6\% respectively. Concerning air pollution in Greece in 2017, mainly due to crisis, the greenhouse gas emissions per capita went below the OECD average (OECD, 2017). But in 2019 the air pollution statistics has changed to 76.7 per 100,000 to 39.6 per 100,000 OECD (OECD, 2019a). That, and other factors brought the share of out-of-pocket expenditure at $4.4 \%$ in comparison to the $3 \%$ of OECD countries for 2017. While some of the country's indicators are better than the average OECD indicators, the population coverage and access to healthcare was at $86 \%$ in comparison to $97 \%$ for OECD countries in 2017 but it is now up to $100 \%$ coverage due to insurance reforms. Currently, the overall healthcare expenditure is at 2.238 USD which is lower than the 3,994 OECD average (OECD, 2019a) or $7.8 \%$ of GDP (OECD, 2019a). In the near future it is expected that Greece will allocate more resources to education and healthcare so that hospitals, clinics and diagnostic health centers will operate under the strictest international quality criteria, policies and regulations; that specialized and experienced healthcare professionals will be indeed trained in elite University 
hospitals; that state-of-the-art technology supports the provision of multidisciplinary, patient-centered services and that innovative methods and techniques are constantly adopted. Offering such world-class facilities and promising benefits to doctors and healthcare professionals of the Greek diaspora, will turn them into key contributors to economic recovery of the country and to the reversal of the "Brain Drain" effect in Greece. Education has a role to play in preparing contemporary societies for an age of Artificial Intelligence (AI) and rapid technological advancements. It is important to realize that only when the society as a whole is healthy, it can envision a bright and inclusive future. We, therefore, need to ensure that such healthy existence is possible in the future. We need to examine the impact that environmental exposures (positive and negative) and the climate change may have on our schools, families and communities. Environmental exposures may be biological, chemical, physical or socio-cultural in nature, all contributing and impacting the human health. Life style choices certainly contribute as well (Papadopoulou, Marouli \& Misseyanni, 2019). When new health-related education programs are developed, all the previous aspects should be taken into consideration.

\section{Findings and Suggestions Regarding the Research Questions}

Here below, we will address each research question, as well as a set of related questions as follows. While discussing the biomedical and healthcare sciences programs that exist in Europe and Greece, we will also discuss the kind of educators and the technological support that are needed, as well as ways to connect these educational and research programs with the health-related industry and centers. The exploration of ways to ensure effectively trained healthcare professionals, or to provide top quality medical services and personalized medicine, or to develop EU-wide collaborations around health issues will inform the discussion of the requirements for the creation of top medical centers of excellence.

\subsection{Q1. What type of programs exist in biomedical and healthcare sciences in Europe and in Greece?}

The educational programs in biomedical and healthcare sciences in Europe and in Greece are quite diverse in nature. The EU "Eurydice" portal publishes descriptions of national education systems in general, comparative reports devoted to specific topics, indicators and statistics, as well as news and articles related to the field of education and there are both public and private, for profit or non-profit institutions (European Commision, 2019c). In this portal the types of Higher Education Institutions in Greece and according to the Greek Constitution (article 16) appear to be public only. It is provided only by Institutions which are legal entities of public law. HEIs enjoy full self-administration and academic freedom. They are subject to state supervision. The government finances them. No private HEIs exist in the country (European Commision, 2019c). Yet, for a number of years private entities operate in Greece most of them validated by European Universities. There are also different entrance requirements for EU HEIs as well as different standards and duration. If the institution is private, the costs vary a lot. A few programs are interdisciplinary in nature. The curricula vary a lot both in terms of content and context. In reference to healthcare field, technology is advancing fast though and healthcare educators and professionals need to assimilate it into 
practice. The data/information that is generated will require that student training and translation of emerging technologies blend in appropriately. (Lytras, Papadopoulou, Marouli \& Misseyanni, 2018; Marouli, Misseyanni, Papadopoulou \& Lytras, 2018; Papadopoulou, Marouli, Misseyanni, \& Lytras, 2016; Misseyanni, Lytras, Papadopoulou \& Marouli, 2018).

Overall, our literature review and examination of European reports pointed to the following main recommendations concerning Greece. There is high need to improve the quality of education system since the average educational outcomes as measured by international tests are low and tertiary education brings fewer benefits than in most other OECD countries. In addition, there is a high need for evaluation of Ministry of Education staff, administrators, school heads, teachers, and for school and university self-evaluations. Greece should continue to introduce assessment frameworks and professional development schemes, enhance pedagogical and managerial autonomy, replace the current university entrance exam with regular and broad assessments of students' learning, supplemented by general aptitude tests. The type of training of students, including vocational training, plus that of physicians and healthcare professionals ought to be reexamined. Private education legislation and policies should be revisited (OECD, 2019a,b; Vincent-Lancrin, Urgel, Joaquin, Kar \& Jacotini et al., 2019).

\subsubsection{Q1a. What kind of educators and healthcare professionals are needed for biomedical and healthcare science programs?}

Before addressing the question one should have in mind the following:

$\circ$ Trends affecting and shaping education and the training of healthcare professionals can be economic, political, social and technological.

o All stakeholders should have as priority the welfare of humans.

Educators all over Europe must be well trained themselves with multiple skills and with terminal degrees the majority of them. There is high need for informaticians, bioinformaticians, statisticians etc. Healthcare professionals should be trained to not only have theoretical knowledge but also be equipped with practical and transferable skills and be quite flexible within a healthcare system that will certainly be changing rapidly in the near future. Furthermore, healthcare professionals should be prepared and well-used to interdisciplinary team work for effective resolution of health problems and even health promotion in the first place. Educators should also be trained to expedite the transfer and analysis of data, leading to improved efficiencies and knowledge. The best type of education should be focusing on mentorship and apprenticeship, as learning has to be lifelong (OECD, 2018).

\subsubsection{Q1b. How to technologically and practically support biomedical and healthcare science programs and move into healthcare digital transformation?}

Countries should allocate enough resources to ensure viable healthcare educational programs and a sustainable healthcare system. While the average OECD Health expenditure is $8.8 \%$, share of GDP, for Greece it is 7.8\% (OECD, 2019a). Hubs of connected medical schools equipped with digital healthcare should be created as well. Special care should be given to equip such programs with the appropriate labs, equipment, 
materials and ICTs. Countries need to enhance the nation's health IT and infrastructure and also to be willing to share technologies. The need for investment on education and translation of emerging technologies and the data/information they generate into healthcare information is high. The need for good understanding of biological systems, IT knowledge about networks and systems, usability, process re-engineering, workflow analysis and redesign is equally high. Countries should be open to explore innovative ideas for the future and they need to invest on the latest equipment and technologies such as Smart Data and Data Analytics, along with Cognitive Computing, and to introduce patientcentric systems in healthcare. Furthermore, they should invest on various resilient smart healthcare automation applications and services and explore various (AI) innovations. Decision makers should re-envision the concept of 'smart healthcare' and 'smart cities', which depend on the use of big data, so that new technologies serve humane urban living. Going from Big Data to Smart Data to Wise Data

Big Data is much more data than information, knowledge or wisdom since not all data is (are) meaningful (Fig.1). Big Data is usually defined around four aspects: data Volume (data at rest), data Velocity (data in motion), data Veracity (data in doubt-reliability) and data Value (optimizing processes and improving outcomes). Recently additional aspects were considered such as Variability (multitude of data dimensions-inconsistencies), Validity (accuracy), Vulnerability (privacy-security issues), Volatility (irrelevant data, historic or not useful) and Visualization (technical limitations (Lytras, Papadopoulou \& Sarirete, 2019 and references within).

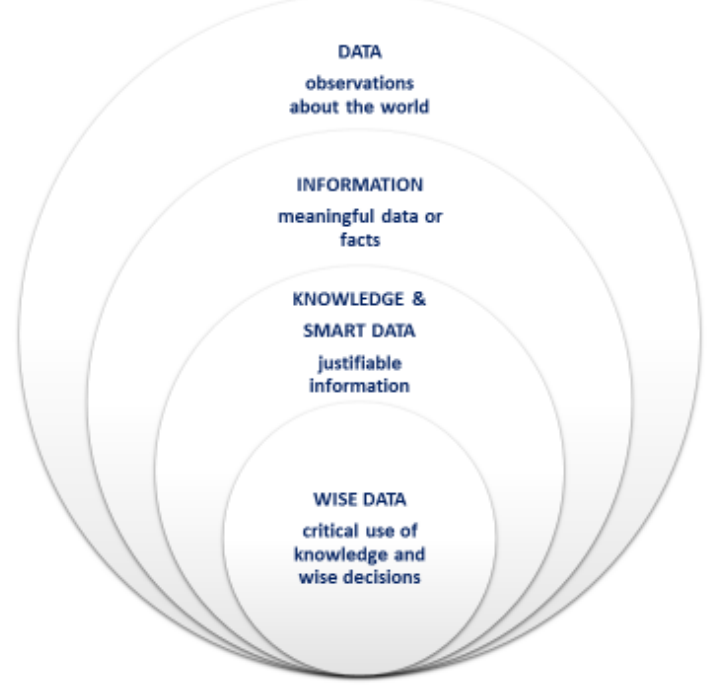

Figure 1. From Data to Information to Knowledge to Wise Data and Decisions Source: Our own

Veracity and Value aspects of Big Data deal with the quality and the usefulness of Big Data. Those two aspects make management a major challenge for most enterprises in terms of quality. The decisive criterion here isn't necessarily the amount of (big) data, but its valuable content (smart) (Lytras \& Papadopoulou, 2018). Turning this data from big to 
smart is the challenge that needs to be addressed today in order to lead to real time assistance hoping to improve medicine and healthcare and provide better, more personalized treatment.

Many steps are required to help countries, including Greece, move into healthcare digital transformation. Mining Big Data originating from smart sensors to be sent to collection points and from there to analytic platforms within Internet of Things (Io'T) systems or properly handle Big Data that is processed, waiting to be turned into actionable information as in the case of Electronic Health Records (EHRs) (European Commission, 2019a) are good examples. Ensure digital innovation and healthcare transformation by analyzing a variety of clinical, financial and administrative data to make wise clinical and business decisions are some additional applications. Investment in state-of-the-art secure technology which supports the provision of multidisciplinary, patient- centered services but also tracks patient mobility are yet additional points of intervention. In the near future, all EU countries should be using cloud computing, EHRs, patient portals, mobile technology, telemedicine, BlockChain technologies, Virtual Reality apps, the Public Health Information Network and also ensure privacy and security and improve interoperability between technologies (Lytras, Papadopoulou \& Sarirete, 2019).

Infrastructure-related and administrative challenges together with lack of sustainable healthcare and survival strategies remain. As is the case for most European countries, Smart Data analysis combined with declines in the cost of generating genomic and proteomic data have made the approaches to DNA sequencing, RNA-sequencing, and high-throughput screening and protein analysis more efficient and effective in terms of analyzing data, they have nevertheless created new challenges in data analysis. Efforts have been made to address those issues and new disciplines have even been formed to tackle the problems. As an example, formal approaches to modeling and simulating regulatory processes in biological systems are better supported by the emerging field of Systems Biology (Lytras \& Papadopoulou, 2018). Most importantly there are not many people with the right expertise to handle such analysis, yet Greece could invite and bring to the country top scientists, physicians and researchers with good job opportunities and decent salaries. Greece needs to further invest in hospitals and various healthcare institutions but also in Greek pharmaceutical companies, allow private higher education to operate as in other European countries, allow collaborations and synergies between the public and private sector and invest in transdisciplinary and interdisciplinary synergies.

Main challenges toward bridging education, ICTs and buman-centered healthcare

A great challenge remains: How to apply Smart Data in ways that lead to wise decisions concerning individual wellness and social welfare, and not focused on market imperatives? This leads to a critical perspective on Smart Data. As a consequence, in one of our studies, a new concept was proposed (i.e. "Wise Data") which aside of the focus of Smart Data on veracity and value also reflects the distinction between individual health and wellness on the one hand, and social improvement, cohesion and longevity on the other, leading to more efficient medical systems, healthier individuals and more socially cohesive societies (Papadopoulou, Lytras \& Marouli, 2018). Whether or not AI and Machine Learning and other ICT technologies will help us move toward societies where the individuals will experience a greater degree of freedom with fulfilling and creative lives, conducive to common good, remains to be seen. 


\subsubsection{Q1c. How to connect biomedical programs with medical centers, pharmaceutical and health-related industry?}

An easy way to connect biomedical programs with medical centers, pharmaceutical and health related industry is through various types of service, work and research collaborations. These collaborations could include internships; practical work study; training on methods, techniques and equipment use, both within the University and with external entities; involvement of students in research projects; Connection of capstone projects with research done in medical centers and the pharmaceutical and health related industry; community service; and voluntary work.

\subsection{Q2. What is needed to create top medical centers of excellence?}

Dreaming and creating top medical centers means that we think together and that we decide together, that is, all stakeholders should have such right. Mainly the will to invest sufficient resources for the creation of medical centers of excellence should be the binding force so that we properly address managerial and policy-making challenges. We need to agree that it is the right time to allocate resources to these medical centers instead of healthdestructive activities (warfare, weapons etc.) By wisely distributing given resources with special emphasis on the reduction of waste and reduction of costs and by educating people on health matters and helping them increase their sense of responsibility. This, of course, assumes active engagement of the patients and all stakeholders. Our focus should be on longevity of the medical centers of excellence, but also the promotion of health and wellness for more years.

\subsubsection{Q2a. How to ensure highly qualified physicians and healthcare professionals?}

Ways to train well-qualified physicians and healthcare professionals include: developing high quality programs in medical, public health and nursing schools headed and taught by top educators and physicians; assessing and evaluating the program learning outcomes. Accepting highly promising students from all range of income and abiding to strict, high quality criteria during selection process, while also maintaining high standards throughout the years of study will also help. It would also be important to increase the practical and team experience and exposure to research and internships in the undergraduate years and to carefully examine the needs of the country for qualified individuals in different fields. Given the increasing use of ICTs in the medical fields, medical and health-related educational programs should incorporate discussion of ethical, social and communication issues throughout their curricula. A very interesting finding for Greece/OECD is that the doctors per capita is 6.1 per $1000 / 3.5$ while the nurses per capita is 3.3 per 1000/8.8 (OECD, 2019). This means that having higher resources of any kind does not necessarily translate to better health outcomes, nor that the resources were spent effectively, and in a way that leads to the proper functioning of the health system.

\subsubsection{Q2b. How to provide top quality medical services and implement personalized medicine?}

All stakeholders involved should agree on the value of investment placed on the development of strong biomedical and healthcare programs. Once well-trained physicians and healthcare professionals come out from such training, they will be well equipped to 
best serve the patients. As long as investment is also placed on hospitals and other healthcare units, the situation will improve. The state budget allocated to the public health sector should be re-examined. Clawback and rebate as practiced by the pharmaceutical industry, as in the case of Greece, should be revisited. Increasingly higher sums returned to the state are raising huge hurdles in the operation of pharmaceutical companies in Greece (OECD, 2019b). What does it mean to have patient-centered medical centers? (O'Dell, 2016). This is a type of mentality not yet of common practice. Countries need to focus on improving prognosis, diagnosis and therapies in order to advance personalized medicine and targeted drug/gene therapy. Implementation should be evidence-base for patient and family engagement in healthcare. Greece especially, needs to develop and sustain new models of care and with special focus on newborns and the aging population. Finally, we need to manage stress before we take things a step forward toward personalized medicine.

\subsubsection{Q2c. How to establish collaborations within EU countries and abide with European and international guidelines and certifications?}

Collaboration among EU countries is easy and necessary (learn by example is often a good solution) and it is supported by the European Union. The implementation of the EU directive on cross-border healthcare should be ensured and the position of European private hospitals should be examined. Patient engagement, collaborative working \& patient pathway analytics to develop and sustain new models of care is needed. The aging population and its impact on medical tourism should also be examined. There are numerous good cases to discuss i.e. how some countries have made effective use of EHRs and e-prescriptions. Collaboration with non-EU countries such as Switzerland or Norway and the US is also not difficult to establish. As an example, Finnish patients are now able to go to a pharmacy in Estonia and retrieve medicine prescribed electronically by their doctor in Finland (European Commission, 2019b). Collaboration with Middle East countries, especially for medical tourism, is another good example for Greece.

\section{Future Recommendations and Conclusions}

The time is right to mount an ambitious effort worldwide to transform the understanding of factors contributing to individual education, health and wellness, with the conviction that success in this effort will advance human societies. Individuals will be healthier if they live in a world where the patients are engaged participants trusting that medical systems and clinicians will closely collaborate in improving their health and with faith to the healthcare system and its practitioners that their main goal is the maintenance of individuals' health as a priority before treatment of disease. 


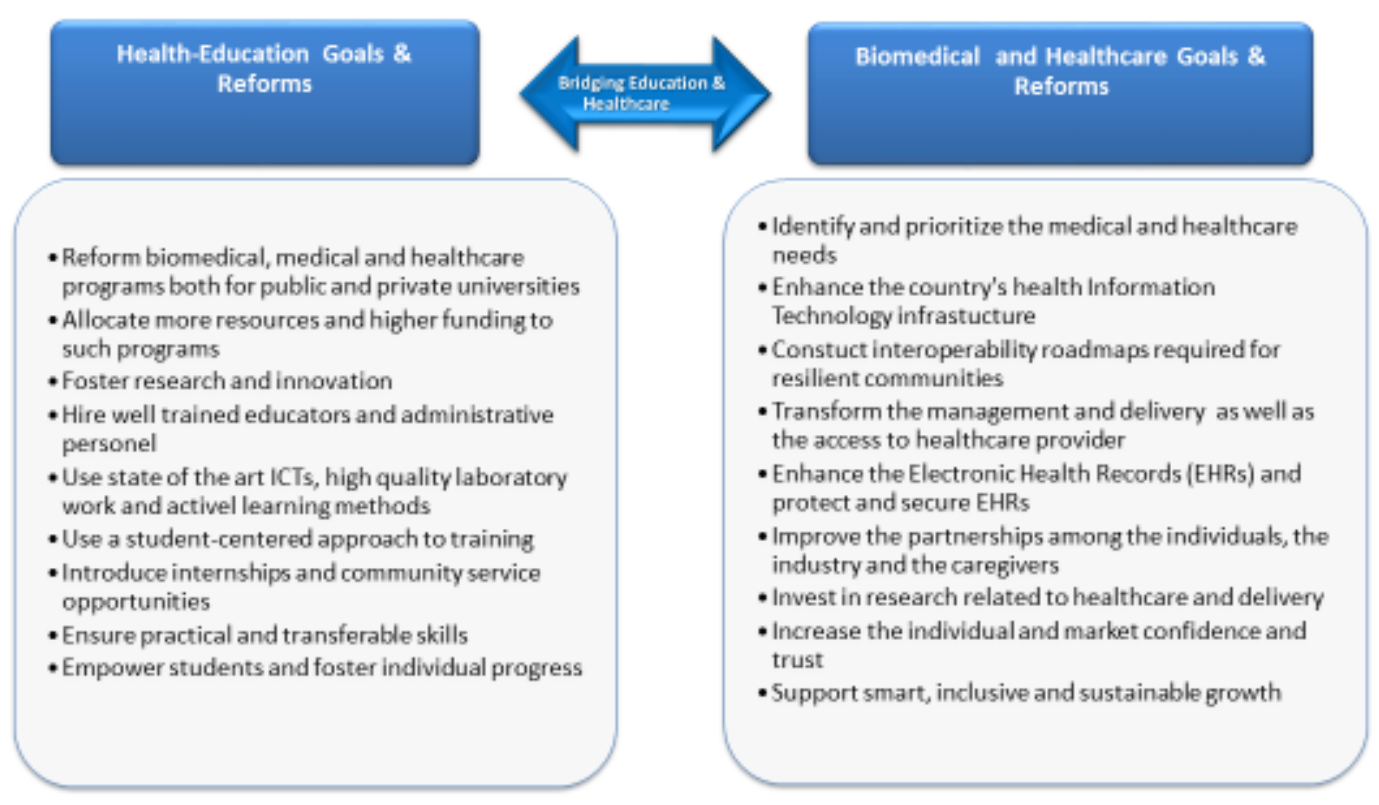

Figure 2. Proposed Reforms

Source: Our own

To move toward sustainable societies with healthy individuals we need to facilitate data access, and storage, data normalization and data management as well as an inseparable connection of data management with ethical considerations Fig. 2. This can be accomplished with the right type of education and training of individuals and the establishment of systems for the maintenance of healthy individuals and societies, but also by taking into consideration the resources that need to be allocated in medicine and medical systems, including the development of powerful computational tools and methods. Greece is currently facing additional problems mainly due to migration of refugees. Will Greece manage to improve its public health services profile, reduce hospital infections and transform its healthcare system into a living example of a solidarity model? For sure a lot of work needs to be done in many sectors. Health policy considerations and governance then become a number one priority for all societies, both at local and global level. The individual engagement to this vision of improving human health and condition of all people is also important. This then will be the time where Big Data not only will have passed successfully through the Smart Data stage but also will have managed to be viewed as Wise Data and therefore Wise Decisions. After all, for individuals to achieve satisfaction in their life, body and mind should coexist in harmony and in health. 
Our recommendations touch upon

$>$ Individual human beings set as priority

$>$ A proper education and training for healthcare practitioners

$>$ Sufficient health resources

$>$ Healthcare for sustainable societies

$>$ International collaboration for improving healthcare systems

$>$ Participatory health governance-a main priority for all societies

$>$ Engaged stakeholders with full trust in medical systems

$>$ Effective and ethical data management leading to Wise Data.

$>$ Main aim: Body mind and spirit harmony

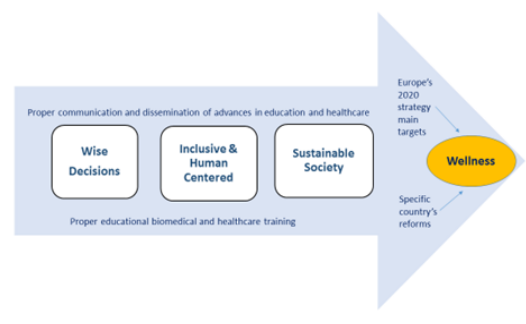

Figure 3. Proposed recommendations

Source: Our own

It is important to bridge education and healthcare in an effective way and, even though it is a big challenge, it can be solved (Fig. 3). Making big data smart implies ability to technically connect relevant data to identify patterns. Turning smart data to wise implies the integral consideration of social, cultural and political dimensions, to ensure the holistic wellbeing of the individual, but also a community that promotes health, wellness and spiritual integrity above anything else. Talented people need to be given the space and also be allowed to creatively form the conditions and manifestations of intelligent and wise delivery.

\section{References}

Economou C., Kaitelidou D., Kentikelenis A., Maresso A., Sisouras A. (2015). The impact of the crisis on the health system and health in Greece. In A. Maresso, P. Mladovsky, S. Thomson, A. Sagan, M. Karanikolos, E. Richardson et al., (editors), Economic crisis, health systems and health in Europe. Country experience. Copenhagen: WHO Regional Office for Europe; (Observatory Studies Series No. 41; http://www.euro.who.int/_data/assets/pdf_file/0010/279820/Web-economic-crisishealth-systems-and-health-web.pdf?ua $=1$, Accessed on 25 November 2019).

Economou C., Kaitelidou D., Karanikolos M. \& Maresso A. (2017). Health Systems in Transition, Greece: Health system review. 19(5):1-192.

European Commission (2019a). Exchange of Electronic Health Records across the EU https://ec.europa.eu/digital-single-market/en/exchange-electronic-health-records-across-eu. Accessed November 25, 2019.

European Commission (2019b). First EU citizens using ePrescriptions in other EU country. https://ec.europa.eu/commission/presscorner/detail/en/IP 18 6808; Accessed November 20, 2019

European Commission (2019c).Greece- Higher Education. https://eacea.ec.europa.eu/nationalpolicies/eurydice/content/higher-education-33_enhttps://eacea.ec.europa.eu/nationalpolicies/eurydice/content/greece en. Accessed November 25, 2019

Eurostat: https://ec.europa.eu/eurostat/web/europe-2020-indicators/visualisations. Accessed November 20, 2019

Lytras, M. D., Papadopoulou, P., Marouli, C., \& Misseyanni, A. (2018). Higher Education Out-of-the-Box: Technology-Driven Learning Innovation in Higher Education. In S. Burton (Ed.), Engaged Scholarship and Civic Responsibility in Higher Education (pp. 67-100). Hershey, PA: IGI Global. doi:10.4018/978-1-5225-3649-9.ch004 
Lytras, M. D. \& Papadopoulou, P. (2018). Applying Big Data Analytics in Bioinformatics and Medicine (pp. 1-465). Hershey, PA: IGI Global. doi:10.4018/978-1-5225-2607-0 https://www.igiglobal.com $/$ pdf.aspx?tid $=182936 \&$ ptid $=177903 \&$ ctid $=15 \& \mathrm{t}=$ Preface

Lytras, M. D., Papadopoulou, P. \& Sarirete, A. (2020). Smart Healthcare: emerging technologies, best practices, and sustainable policies. In M. D. Lytras, A. Sarirete (Ed.). In Next Gen Tech Driven Personalized Med \& Smart Healthcare, Innovation in Health Informatics, Academic Press, (pp. 3-38). doi.org/10.1016/B978-0-12-819043-2.00001-0.

Marouli, C., Misseyanni, A., Papadopoulou, P. \& Lytras, M.D., (2018). A New Vision for Higher Education: Lessons from Education for the Environment and Sustainability. In A. Misseyanni, M. D. Lytras, P. Papadopoulou \& C. Marouli, (Editors), Active Learning Strategies in Higher Education:Teaching for Leadership, Innovation and Creativity, Emerald Publishing Limited, Bingley, UK. pp.361 - 387.

Misseyanni, A., Lytras, M.D., Papadopoulou, P. \& Marouli, C. (2018). Introduction. In A. Misseyanni, M. D. Lytras, P. Papadopoulou, C. Marouli (Editors), Active Learning Strategies in Higher Education:Teaching for Leadership, Innovationa and Creativity, Emerald Publishing Limited, Bingley, UK. pp.1-13.

Papadopoulou, P., Marouli, C., Misseyanni, A. \& Lytras, M. (2016). Editorial Preface, Special Issue on Teaching in Higher Education: Active Learning, and New Teaching Methodologies, International Journal of Knowledge Society Research (JKSR), 7(4).https://www.igi-global.com/journal/internationaljournal-knowledge-society-research $/ 1180$

Papadopoulou, P., Lytras, M., \& Marouli, C. (2018). Bioinformatics as Applied to Medicine: Challenges Faced Moving from Big Data to Smart Data to Wise Data. In M. Lytras, \& P. Papadopoulou (Eds.), Applying Big Data Analytics in Bioinformatics and Medicine (pp. 1-25). Hershey, PA: IGI Global. doi:10.4018/978-1-5225-2607-0.ch001

Papadopoulou, P. Marouli, C. \& Misseyanni A. (2019). Book Preface in P. Papadopoulou, C. Marouli \& A. Misseyanni, (Editors), Environmental Exposures and Human Health Challenges (pp. 1-449). Hershey, PA: IGI Global. doi:10.4018/978-1-5225-7635-8.https://www.igiglobal.com/book/environmental-exposures-human-health-challenges/208851

Papadopoulou, P., Daniella L. \& Lytras, M (2019). Virtual and Augmented Reality in Medical Education and Training: Innovative Ways for Transforming Medical Education in the 21st Century in Lytras, M. D., Aljohani, N., Daniela, L., \& Visvizi, A. (Eds.), Cognitive Computing in Technology-Enhanced Learning (pp. 1-350). Hershey, PA: IGI Global.

O'Dell M. L. (2016). What is a Patient-Centered Medical Home?. Missouri medicine, 113(4), 301-304.

OECD/European Observatory on Health Systems and Policies (2017a), Greece: Country Health Profile 2017, State of Health in the EU, OECD Publishing, Paris/European Observatory on Health Systems and Policies, Brussels, https://doi.org/10.1787/9789264283404-en. Accessed on 25 November 2019).

OECD (2017b), Health at a Glance 2017: OECD Indicators, OECD Publishing, Paris, https://doi.org/10.1787/health glance-2017-en. Accessed on 25 November 2019).

OECD (2018), Education at a Glance 2018: OECD Indicators, OECD Publishing, Paris, https://dx.doi.org/10.1787/eag-2018-en. Accessed on 25 November 2019).

OECD (2019a), Health at a Glance 2019: OECD Indicators, OECD Publishing, Paris, https://doi.org/10.1787/4dd50c09-en. Accessed on 25 November 2019).

OECD (2019b), OECD Regional Statistics (database), http://dx.doi.org/10.1787/region-data-en

OECD (2019c), "Regional education", OECD Regional Statistics (database), https://doi.org/10.1787/213e806c-en. Accessed on 25 November 2019).

WHO Regional Office for Europe (2016b). Greece: highlights on health and well-being.

Copenhagen, WHO Regional Office for Europe (http://www.euro.who.int/_data/assets, Accessed November 25, 2019).

WHO Regional Office for Europe (2019). Monitoring and documenting systemic and health effects of health reforms in Greece (2019). Copenhagen, WHO Regional Office for Europe. http://www.euro.who.int/en/countries/greece/publications/monitoring-and-documentingsystemic-and-health-effects-of-health-reforms-in-greece-2019. Accessed November 25, 2019.

World Health Organization. (2013). Global action plan for the prevention and control of noncommunicable diseases 2013-2020. World Health Organization. https://apps.who.int/iris/handle/10665/94384. Accessed November 25, 2019. 
World Bank (2019). World development indicators database 2019 https://www.worldbank.org/ ; http://wdi.worldbank.org/tables. Accessed 25 November 2019).

Vincent-Lancrin, S., Urgel, Joaquin, Kar S. \& Jacotini G. et al. (2019), Measuring Innovation in Education 2019: What Has Changed in the Classroom?, Educational Research and Innovation, OECD Publishing, Paris, https://doi.org/10.1787/9789264311671-en. 